\title{
Male-Female Differences in Transitions from First Drug Opportunity to First Use: Searching for Subgroup Variation by Age, Race, Region, and Urban Status
}

\author{
MICHELLE L. VAN ETTEN, Ph.D. ${ }^{1}$ and JAMES C. ANTHONY, Ph.D. ${ }^{2}$
}

\begin{abstract}
Recent studies in the United States suggest that male-female differences in the prevalence of drug use may result from sex differences in opportunities to use drugs rather than from differences in the likelihood of making a transition into drug use once an opportunity has occurred. That is, men have more opportunities to try drugs, but women appear to be just as likely as men to initiate drug use when given the opportunity to do so. This paper examines whether this general observation holds for subgroups defined by age or birth cohort, race/ethnicity, geographic region, and urban status. We analyzed data from the 1991, 1992, and 1993 National Household Surveys on Drug Abuse. We found general consistency across the subgroups studied. Males were more likely than females to have opportunities to use drugs, but the sexes were equally likely to make a transition into drug use once an opportunity had occurred to try a drug. The implications of this evidence are discussed in relation to the epidemiology and prevention of drug use and with respect to future research on sex and gender differences in drug involvement.
\end{abstract}

\section{INTRODUCTION}

T HE AIM OF THIS REPORT is to examine potential subgroup variation in our recent findings based on analyses of data from the National Household Surveys on Drug Abuse (NHSDA). In these analyses, we found evidence that well-established male-female differences in the prevalence of drug use might be traced back to differences in the probability of having an initial opportunity to try drugs rather than to differences in the probability of becoming a user once an opportunity has occurred., ${ }^{1,2}$ Our first paper on this topic was based on the total population surveyed for the 1993 NHSDA, and our second paper replicated these findings across nine inde- pendent NHSDA samples from 1979 to 1994. In the latter report, time trends from 1990 to 1994 revealed an increase in the conditional probability of illicit drug use, given the opportunity to use, for marijuana, cocaine, hallucinogens, and heroin. However, sex differences in this conditional probability were not observed. In the present report, we search for variation in our original findings of no sex differences in the conditional probability of drug use, given opportunity, across subgroups defined by age or birth cohort, race/ethnicity, geographic region, and urban status, in order to determine the specificity or generality of our original findings.

We begin with subgroups defined by age (birth cohort), race/ethnicity, geographic region, and

${ }^{1}$ Department of Psychiatry, University of Michigan, Ann Arbor, Michigan.

${ }^{2}$ Bloomberg School of Public Health, The Johns Hopkins University, Baltimore, Maryland. 
urban vs. rural setting based on a wealth of prior research demonstrating the significant influence of these factors on drug use. For example, recent data from the 1999 NHSDA survey illustrate that illicit drug use varies by these factors. ${ }^{3}$ Regarding age, drug use is most prominent among people aged 18-20 years. Noteworthy differences in prevalence of illicit drug use are also demonstrated across race/ethnicity: whites, $6.6 \%$; blacks, 7.7\%; American Indians / Alaskan Natives, $10.6 \%$; Asians, $3.2 \%$; multiple race, $11.2 \%$; and Hispanics, $6.8 \%$. Examination of illicit drug use across geographic regions reveals greater illicit drug use in the West $(7.9 \%)$ and Northeast $(7.4 \%)$ relative to the South (5.6\%) and Midwest (6.7\%). Finally, rates of illicit drug use also varied by level of urbanicity, with greater use in increasingly urban settings. Rates of illicit drug use were $4.2 \%$ in completely rural areas, $5.2 \%$ in nonmetropolitan areas, and $7 \%$ in various sized metropolitan areas. Our prior work on drug opportunities also suggests that there may be race/ethnicity variation in the likelihood of making a transition from initial drug opportunity to drug use. ${ }^{1}$ Given the documented influence of these factors on drug use, we now seek to explore whether these factors may differentially impact drug opportunities, or use, given opportunity, depending on sex (i.e., interaction effects).

This line of research has its roots in prior epidemiological research on male-female differences in the prevalence of drug dependence. For example, evidence from the National Comorbidity Survey (1990-1991) suggested that a higher prevalence of drug dependence in males vs. females might generally be traced back to male-female differences in the prevalence of drug use rather than to differences in the likelihood of becoming dependent once drug use had occurred. ${ }^{4}$ Here, we suggest that sex differences in drug use can be traced back even further to the stage of early opportunities to use the drugs. In effect, these findings suggest that females are not more insulated than males against the probability of becoming increasingly involved in progressive levels of drug involvement once a previous level of involvement has been attained, as might be deduced by a glance at the higher prevalence rates of drug problems in men than women. Rather, the insulation may occur only at the initial level of opportunities to use drugs.

In addition to probing the consistency of our recent findings, 1,2 this study complements the vast existing literature on sex differences in drug use, abuse, and dependence by highlighting sex differences or nondifferences at earlier stages of drug involvement (i.e., initial drug opportunity). National surveys in the United States and Europe have noted repeatedly the elevated risk of illicit drug use and abuse for males vs. females. ${ }^{4-7}$ Sex differences among drug abusers in psychiatric comorbidity ${ }^{4,8}$ personality correlates, ${ }^{9}$ and specific aspects of drug use ${ }^{10}$ have also been explored. Anglin et al. ${ }^{11,112}$ have described sex differences in initiation of heroin use and transition to dependence, yet this type of knowledge on sex differences in drug initiation is relatively sparse in comparison to our understanding of sex differences in later stages of drug involvement. The literature that has examined early opportunitites to try illicit drugs is sparse in itself ${ }^{13-16}$ and has not attended to sex differences in early drug opportunities. By focusing on sex differences at the level of early opportunities to try illicit drugs, this study adds new evidence on sex differences in drug involvement.

\section{MATERIALS AND METHODS}

The methods for this study are essentially identical to those used and reported in past technical reports of the NHSDA ${ }^{17-19}$ as well as our three prior papers on data from the NHSDA with respect to the topic of initial opportunities to start taking illicit drugs. ${ }^{1,2,20}$ In brief, the population sampled for the NHSDA surveys has consisted of noninstitutionalized civilian residents of the United States, aged $\geq 12$ years. In this report, we focus on the aggregated data from three nationally representative samples that were drawn using multistage probability sampling methods in 1991, 1992, and 1993. The total aggregate sample consists of 87,915 respondents, with a male/female ratio of 0.81 . Table 1 describes the sample size, by sex, for each subgroup under study in this report.

The NHSDA assessments were conducted in private by trained interviewers who administered a highly standardized interview schedule or questionnaire. Self-administered answer sheets were used to minimize underreporting of sensitive issues, such as illicit drug use. Response rates ranged from $79 \%$ to $84 \%$ across these survey years. Informed consent was obtained under approved research protocols. 
Table 1. Unweighted Sample Size, by Sex, For Each Subgroup Under Study

\begin{tabular}{|c|c|c|c|}
\hline Subgroup & $\begin{array}{l}\text { Total no. of } \\
\text { participants }\end{array}$ & $\begin{array}{l}\text { No. of } \\
\text { males }\end{array}$ & $\begin{array}{l}\text { No. of } \\
\text { females }\end{array}$ \\
\hline \multicolumn{4}{|l|}{ Age $\left(\right.$ years) ${ }^{a}$} \\
\hline $12-17$ & 22,237 & 11,188 & 11,049 \\
\hline $18-29$ & 31,360 & 14,089 & 17,271 \\
\hline $30-44$ & 23,337 & 9,857 & 13,480 \\
\hline $45+$ & 10,981 & 4,335 & 6,646 \\
\hline \multicolumn{4}{|l|}{ Race } \\
\hline White & 42,206 & 19,299 & 22,907 \\
\hline African American & 20,744 & 8,544 & 12,200 \\
\hline Hispanic & 21,958 & 10,138 & 11,820 \\
\hline Other ${ }^{b}$ & 3,007 & 1,488 & 1,519 \\
\hline \multicolumn{4}{|l|}{ U.S. region } \\
\hline Northeast & 14,098 & 6,101 & 7,997 \\
\hline North Central & 15,688 & 6,938 & 8,750 \\
\hline South & 34,290 & 15,353 & 18,937 \\
\hline West & 23,839 & 11,077 & 12,762 \\
\hline \multicolumn{4}{|l|}{ Urban status } \\
\hline Center MSA ${ }^{c}$ & 22,787 & 10,009 & 12,778 \\
\hline Outside center MSA & 24,049 & 11,117 & 12,932 \\
\hline Not in MSA & 41,079 & 18,343 & 22,736 \\
\hline Total & 87,915 & 39,469 & 48,446 \\
\hline
\end{tabular}

From the National Household Survey on Drug Abuse (aggregated 1991-1993 survey data).

aThese age groups in 1991-1993 correspond to the following birth cohorts, respectively: 1974-1981, 1962-1975, 1947-1963, 1946 and earlier.

${ }^{\mathrm{b}}$ Respondents in the Other race category were not included in analyses due to small sample size.

'MSA, metropolitan statistical area (includes Chicago, Denver, Los Angeles, Miami, New York, and Washington, DC).

All survey respondents were asked, "About how old were you when you first had a chance to try marijuana or hashish if you had wanted to?" as well as "About how old were you the first time you actually used marijuana or hashish, even once?" The wording of these questions has remained essentially unchanged across the survey years. Analogous questions are asked about cocaine, heroin, and hallucinogens.

As in our previous reports on this topic, three characteristics are of primary interest. The first characteristic is the estimated proportion of males and females who have had an opportunity to try marijuana, cocaine, hallucinogens, and heroin. The second characteristic is the estimated probability of eventually using each drug, given that an opportunity to use the drug has been experienced. The third characteristic of interest is the estimated proportion making a rapid transition into drug use once the opportunity to try the drug has occurred. This estimate is based on a comparison of the age at first opportunity to try each drug vs. the age of first use of the drug. When the age at first opportunity equals the age of first drug use, there has been a relatively rapid transition from the initial opportunity to the first drug use. $^{2}$ Estimated prevalence proportions and prevalence ratios are used to convey the magnitude of male-female variation in the tabled results.

Subgroups under study included the following: age in 1991-1993/birth cohort (12-17 years, 1974-1981; 18-29 years, 1962-1975; 30-44 years, 1947-1963; 45 years and older, 1890-1948 and prior), race/ethnicity (white, African American, Hispanic), geographic region (Northeast, North Central, South, West), and urban status (residing in the city center of one of the NHSDA metropolitan statistical areas [MSA], outside the city center of an MSA, not in a MSA). Both geographic region and urban status were determined at the time of the interview. Note that the birth cohorts corresponding to each age category overlap by 2 years per group because of the nature of our aggregate data from multiple survey years. However, there has been no double counting of individual subjects. The birth cohort and age categories represent independent subsamples with no overlap.

Estimates of prevalence proportions and their standard errors for each subgroup in these analyses were derived by standard NHSDA procedures that take into account sampling probabilities as well as poststratification adjustment factors to compensate for variation in survey nonresponse. This was accomplished using SUDAAN software. ${ }^{21}$ Statistical differences in estimated prevalence proportions between males and females were tested with alpha set at 0.05 .

\section{RESULTS}

There is evidence of a relative male excess in the estimated probability of having an opportunity to try illicit drugs, as shown in Tables 2, 3, 4 , and 5 for subgroups defined by age/birth cohort, race/ethnicity, geographic region, and urban status, respectively. Across almost all subgroups defined by age/cohort, race/ethnicity, geographic region, and urban status, males were more likely than females to have an opportunity to use marijuana, cocaine, hallucinogens, and heroin $(p<0.001)$.

One exception to this general finding was ob- 
Table 2. Age-Specific Male-Female Differences in Occurrence of Initial Drug Opportunities, Probability of Drug Use Given That an Opportunity Has Occurred, and Probability of Making a Rapid Transition from First Opportunity to First Use Given That an Opportunity Has Occurred

\begin{tabular}{|c|c|c|c|c|c|c|c|c|c|c|c|c|}
\hline \multirow[b]{2}{*}{$\begin{array}{l}\text { Age drug } \\
\text { (years) }\end{array}$} & \multicolumn{4}{|c|}{$\begin{array}{l}\text { Estimated proportion with } \\
\text { a drug opportunity }\end{array}$} & \multicolumn{4}{|c|}{$\begin{array}{l}\text { Estimated proportion who used, } \\
\text { given opportunity }\end{array}$} & \multicolumn{4}{|c|}{$\begin{array}{l}\text { Estimated proportion making } \\
\text { a rapid transition into } \\
\text { drug use, given opportunity }\end{array}$} \\
\hline & Male & Female & $\begin{array}{l}M: F \\
\text { ratio }\end{array}$ & $\mathrm{p}$ value & Male & Female & $\begin{array}{l}M: F \\
\text { ratio }\end{array}$ & $\mathrm{p}$ value & Male & Female & $\begin{array}{l}M: F \\
\text { ratio }\end{array}$ & $\mathrm{p}$ value \\
\hline \multicolumn{13}{|l|}{$12-17$} \\
\hline Mari & 3.79 & 28.04 & 1.21 & $0.001^{*}$ & 38.27 & 37.29 & 1.03 & 0.596 & 20.80 & 20.83 & 1.00 & 0.984 \\
\hline Coca & .76 & & 0. & 0.159 & 4.88 & & 0.79 & & 10.62 & 13.68 & 0.78 & 0.064 \\
\hline Hall & 7.12 & 7.5 & 0.94 & 0.490 & 42.99 & 38.54 & 1.12 & 0.289 & 35.10 & 28.22 & 1.24 & 0.984 \\
\hline Hero & 3.37 & 3.51 & 0.96 & 0.767 & 6.91 & 6.13 & 1.13 & 0.764 & 4.87 & 4.82 & 1.01 & 0.984 \\
\hline \multicolumn{13}{|l|}{$18-29$} \\
\hline Marij & .80 & 68.39 & 1. & $0.001^{*}$ & .65 & 71.83 & 1.0 & & 9.65 & 41.10 & 6 & 0.238 \\
\hline Cocai & 3.03 & 34.46 & 1.25 & $0.001^{*}$ & 49.82 & 46.11 & 1.08 & $32 *$ & 34.41 & 31.80 & 1.08 & 0.099 \\
\hline Hal & 4.63 & & & & 67.97 & & & & & & 0.97 & 0.412 \\
\hline Herc & .91 & 80 & 1 & 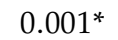 & 18.39 & 17.92 & 1.03 & 3 & 15.07 & 14.27 & 1.06 & 0.772 \\
\hline \multicolumn{13}{|l|}{$30-44$} \\
\hline Mari & 59 & & 1 & & 80 & & & & 48.31 & & 1. & 0.363 \\
\hline Coca & .94 & 2 & 1. & $001^{*}$ & 57.09 & 54 & 10 & 0 & 42 & 4 & 1.03 & 0.490 \\
\hline Hall & 30.33 & 17.30 & 1.75 & 0 & 69.43 & 64 & 1.08 & & 53.22 & 51.90 & 1.03 & 0.610 \\
\hline Heroi & 12.73 & & 2.53 & $0.001^{*}$ & 24.33 & 30.33 & 0.80 & 0.158 & 18.51 & 26.08 & 0.71 & 0.073 \\
\hline \multicolumn{13}{|l|}{$45+$} \\
\hline Mari & 4.76 & 17.7 & 1. & $0.001^{*}$ & 50.99 & & 1.06 & & 39.65 & & 1.06 & 0.496 \\
\hline Coca & 10.19 & & 2.6 & 0.0 & 32.76 & 26.18 & 1.25 & 0.250 & 27.23 & & 1.19 & 0.424 \\
\hline Hall & 4.90 & 1. & 3.7 & & 46.24 & & 1.06 & 0.810 & 41.73 & 40.94 & 1.01 & 0.936 \\
\hline Heroin & 4.27 & 0.90 & 4.74 & $0.001^{*}$ & 10.64 & 12.04 & 0.88 & 0.772 & 8.28 & 8.58 & 0.82 & 0.944 \\
\hline
\end{tabular}

From the National Household Surveys on Drug Abuse, 1991-1993 (aggregated).

${ }^{a}$ In this table and Tables 3,4, and 5, male-female differences that are statistically significant at the conventional level of $p<0.05$ are indicated by a single asterisk. Rapid transition was defined operationally as follows: age at initial use equals age at initial opportunity.

served within the subgroup of 12-17-year-olds. Here, males were more likely than females to have an opportunity to use marijuana but not more likely to have an opportunity to use cocaine, hallucinogens, and heroin. That is, a male-female difference in the probability of having an opportunity to use marijuana was present across all age categories, whereas male-female differences in the probability of having an opportunity to use cocaine, hallucinogens, and heroin were not statistically significant by conventional standards in the 12-17-year-old category (alpha $=0.05$ ). To summarize, of 56 male-female comparisons with respect to the probability of having an initial opportunity to try each drug, 53 showed a male excess, with statistical significance at the $p<0.001$ level.

In contrast to the general finding of male-female differences in the probability of having an opportunity to use drugs across most subgroups under study, there was little evidence of male-female differences in the likelihood of eventually using the various drugs, once an opportunity had occurred, across the various subgroups (Tables 2, 3,4 , and 5). In 56 tests of male-female differences in the probability of making the transition from opportunity to use, only 7 of the observed differences were statistically significant $(p<0.05)$.

As to the estimated probability of making a rapid transition from initial opportunity to initial use, in 56 tests we observed only 3 statistically significant male-female differences (Tables 2, 3, 4, and 5). Within the limits of these NHSDA data on age at first use, males are not more likely than females to rush into drug use once an opportunity presents itself. The estimated probability of using within 1 year of the initial opportunity does not vary substantially for males vs. females.

\section{DISCUSSION}

These results, based on nationally representative samples collected in the United States between 1991 and 1993, tend to support the thesis that male-female differences in the prevalence of 
Table 3. Race/Ethnicity-Specific Male-Female Differences in Occurrence of Initial Drug Opportunities, Probability of Drug Use Given That an Opportunity Has Occurred, and Probability of Making a Rapid Transition from First Opportunity to First Use Given That an Opportunity Has Occurred

\begin{tabular}{|c|c|c|c|c|c|c|c|c|c|c|c|c|}
\hline \multirow[b]{2}{*}{ Race/ethnicity druga } & \multicolumn{4}{|c|}{$\begin{array}{l}\text { Estimated proportion with } \\
\text { a drug opportunity }\end{array}$} & \multicolumn{4}{|c|}{$\begin{array}{l}\text { Estimated proportion who used, } \\
\text { given opportunity }\end{array}$} & \multicolumn{4}{|c|}{$\begin{array}{l}\text { Estimated proportion making } \\
\text { a rapid transition into } \\
\text { drug use, given opportunity }\end{array}$} \\
\hline & Male & Female & $\begin{array}{l}M: F \\
\text { ratio }\end{array}$ & $\mathrm{p}$ value & Male & Female & $\begin{array}{l}M: F \\
\text { ratio }\end{array}$ & $\mathrm{p}$ value & Male & Female & $\begin{array}{l}M: F \\
\text { ratio }\end{array}$ & $\mathrm{p}$ value \\
\hline \multicolumn{13}{|l|}{ White } \\
\hline Marijuana & 8.63 & 45.68 & 1.28 & $0.001^{*}$ & 66.87 & 66.47 & 1.01 & 0.767 & 41.84 & 41.54 & 1.01 & 0.803 \\
\hline Cocaine & 28.61 & 19.50 & 1.47 & $0.001^{*}$ & 50.92 & 48.47 & 1.05 & 0.158 & 37.07 & 35.51 & 1.04 & 0.358 \\
\hline inogens & 19.74 & 11.76 & 1.68 & $1^{*}$ & 65.57 & 62.43 & 1.05 & 0.139 & 49.70 & 49.44 & 1.01 & 0.897 \\
\hline Heroin & 7.27 & & 2.23 & $0.001^{*}$ & 17.73 & 19.96 & 0.89 & 0.472 & 13.61 & 16.92 & 0.80 & 0.263 \\
\hline \multicolumn{13}{|l|}{ African American } \\
\hline Marij & 8.39 & 41.25 & 1.42 & 0.0 & 69.45 & 62.64 & 1.11 & 0.0 & 46.90 & 86 & 1.05 & 0.258 \\
\hline Coca & 29.09 & 16.32 & 1.78 & $0.001^{*}$ & 46.79 & 39.01 & 1.20 & $0.004^{*}$ & 36.32 & 30.46 & 1.19 & $0.019^{*}$ \\
\hline Hallucinogen & 8.79 & 3.54 & 2.48 & $0.001^{*}$ & 57.57 & 51.30 & 1.12 & 0.308 & 47.35 & 43.01 & 1.10 & 0.459 \\
\hline Hero & .45 & 3.91 & 2.42 & $0.001^{*}$ & 22.62 & 29.50 & 0.77 & 0.190 & 19.02 & 24.01 & 0.79 & 0.289 \\
\hline \multicolumn{13}{|l|}{ Hispanic } \\
\hline Marijuana & 58.41 & 33.98 & 1.72 & $0.001^{*}$ & 58.25 & 59.45 & 0.98 & 0. & 37.74 & 40.62 & 0.93 & 0.131 \\
\hline Coca & 29.59 & 14.58 & 2.03 & $0.001^{*}$ & 44.92 & 46.44 & 0.97 & 0.535 & 34.52 & 34.58 & 1.00 & 0.976 \\
\hline $\mathrm{Ha}$ & 11.07 & & 1.7 & 0.0 & 71.46 & & 1.12 & 0. & 61.47 & $4 \mathrm{c}$ & 1.23 & $0.009^{*}$ \\
\hline Heroin & 6.76 & 2.73 & 2.48 & $0.001^{*}$ & 27.72 & 21.21 & 1.31 & 0.164 & 22.07 & 13.87 & 1.59 & 0.037 \\
\hline
\end{tabular}

From the National Household Surveys on Drug Abuse, 1991-1993 (aggregated).

a Respondents in races other than those listed were not included in analyses due to small sample size.

bee Table 2, footnote ${ }^{\mathrm{a}}$.

Table 4. Region-Specific Male-Female Differences in Occurrence of Initial Drug Opportunities, Probability of Drug Use Given That an Opportunity Has Occurred, and Probability of Making a Rapid Transition from First Opportunity to First Use Given That an Opportunity Has Occurred

\begin{tabular}{|c|c|c|c|c|c|c|c|c|c|c|c|c|}
\hline \multirow[b]{2}{*}{ Region drug } & \multicolumn{4}{|c|}{$\begin{array}{l}\text { Estimated proportion with } \\
\text { a drug opportunity }\end{array}$} & \multicolumn{4}{|c|}{$\begin{array}{l}\text { Estimated proportion who used, } \\
\text { given opportunity }\end{array}$} & \multicolumn{4}{|c|}{$\begin{array}{l}\text { Estimated proportion making } \\
\text { a rapid transition into } \\
\text { drug use, given opportunity }\end{array}$} \\
\hline & Male & Female & $\begin{array}{l}M: F \\
\text { ratio }\end{array}$ & $\mathrm{p}$ value & Male & Female & $\begin{array}{l}M: F \\
\text { ratio }\end{array}$ & $\mathrm{p}$ value & Male & Female & $\begin{array}{l}M: F \\
\text { ratio }\end{array}$ & value \\
\hline \multicolumn{13}{|l|}{ Northeast } \\
\hline Marijuana & 3.19 & 43.31 & 1.34 & $0.001^{*}$ & 7.02 & 64.85 & 1.03 & 0.435 & 44.79 & 42.20 & 1.06 & 0.254 \\
\hline Cocaine & .85 & 1 & 1.61 & $0.001^{*}$ & 3.04 & & 1.1 & & 41.32 & 36.27 & 1.14 & 0.147 \\
\hline Hall & 7.25 & & 1.5 & * & & & 1.0 & & 49 & 50 & 0.97 & 0.757 \\
\hline Heroin & 7.22 & 3 & 2. & 0 & 8 & & 0. & & 16 & 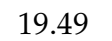 & 0.84 & 0.660 \\
\hline \multicolumn{13}{|l|}{ North Central } \\
\hline Marijl & 5.91 & 4 & 1.3 & P & 7.26 & 6 & 1.04 & & 42.88 & 41.17 & 1.04 & 0.412 \\
\hline $\mathrm{Coc}$ & 1.63 & 1 & 1.61 & & 48.55 & 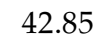 & 1.13 & & 36.62 & 2.03 & 1.14 & 0.095 \\
\hline Hal & 16.16 & & 1.81 & $*$ & 7.97 & 58.59 & 1.16 & $0.020^{*}$ & 51. & 50.07 & 1.03 & 0.674 \\
\hline Hero & 51 & 1 & 2.32 & $.001^{*}$ & 19.57 & 22.41 & 0.87 & 0.589 & 15.23 & 19.85 & 0.77 & 0.368 \\
\hline \multicolumn{13}{|l|}{ South } \\
\hline Mari & 5.21 & 0.59 & 1. & P & 63.50 & 63 & 1.0 & & 9 & 40 & 0.99 & 0.741 \\
\hline Coca & 1 & & 1 & 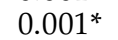 & 43.97 & 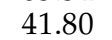 & 1. & 0 & 21 & 20 & 1.04 & 0.638 \\
\hline Hall & 15.42 & & 1.89 & 0 & 60.40 & 59.84 & 1.01 & & 49.20 & 46.27 & 1.06 & 0.599 \\
\hline Hero & 6.76 & 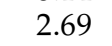 & 2.51 & $0.001^{*}$ & 16.44 & 18.44 & 0.89 & 0.596 & 13.89 & 15.51 & 0.90 & 0.653 \\
\hline \multicolumn{13}{|l|}{ West } \\
\hline Mari & 4.17 & 52.8 & & & 69.51 & & 0.99 & & 43.05 & & 0.98 & 0.726 \\
\hline Coca & 3.45 & 25. & 1.3 & 0.00 & 55.93 & 56.36 & 0.99 & & 40.60 & & 1.01 & 0.904 \\
\hline Hall & 21.96 & 16. & 1.3 & & 69.71 & & & & 51.62 & 51.09 & 1.01 & 0.889 \\
\hline Heroin & 9.09 & 4.64 & 1.96 & $0.001^{*}$ & 20.39 & 23.93 & 0.85 & 0.363 & 16.15 & 18.20 & 0.89 & 0.617 \\
\hline
\end{tabular}

From the National Household Surveys on Drug Abuse, 1991-1993 (aggregated).

aSee Table 2, footnote ${ }^{\text {. }}$. 
Table 5. Urban Status-Specific Male-Female Differences in Occurrence of Initial Drug Opportunities, Probability of Drug Use Given That an Opportunity Has Occurred, and Probability of Making a Rapid Transition from First Opportunity to First Use Given That an Opportunity Has Occurred.

\begin{tabular}{|c|c|c|c|c|c|c|c|c|c|c|c|c|}
\hline \multirow[b]{2}{*}{$\begin{array}{l}\text { Urban } \\
\text { status drug }\end{array}$} & \multicolumn{4}{|c|}{$\begin{array}{l}\text { Estimated proportion with } \\
\text { a drug opportunity }\end{array}$} & \multicolumn{4}{|c|}{$\begin{array}{l}\text { Estimated proportion who used, } \\
\text { given opportunity }\end{array}$} & \multicolumn{4}{|c|}{$\begin{array}{l}\text { Estimated proportion making } \\
\text { a rapid transition into } \\
\text { drug use, given opportunity }\end{array}$} \\
\hline & Male & Female & $\begin{array}{l}M: F \\
\text { ratio }\end{array}$ & $\mathrm{p}$ value & Male & Female & $\begin{array}{l}M: F \\
\text { ratio }\end{array}$ & $\mathrm{p}$ value & Male & Female & $\begin{array}{l}M: F \\
\text { ratio }\end{array}$ & $\mathrm{p}$ value \\
\hline \multicolumn{13}{|l|}{ City center } \\
\hline \multicolumn{13}{|l|}{ In MSA ${ }^{b}$} \\
\hline Marijuana & 2.44 & 33.30 & 1.57 & $0.001^{*}$ & 70.54 & 69.81 & 1.01 & 0.689 & 51.97 & 49.37 & 1.05 & 0.150 \\
\hline Cocaine & 8.26 & 16.26 & 1.74 & $0.001^{*}$ & 55.56 & 49.76 & 1.12 & $0.018^{*}$ & 44.80 & 38.25 & 1.17 & $0.003^{*}$ \\
\hline Hallı & 12.71 & 5.89 & 2.16 & $0 .($ & 69.90 & 65.93 & 1.06 & 0.352 & 55.29 & 49.73 & 1.11 & 0.150 \\
\hline Heroin & 7.54 & 3.2 & 2.31 & $0.001^{*}$ & 27.75 & 27.17 & 1.02 & 0.889 & 23.55 & 20.59 & 1.14 & 0.484 \\
\hline \multicolumn{13}{|l|}{ Not city center } \\
\hline \multicolumn{13}{|l|}{ In MSA } \\
\hline Marijuana & 56.84 & 43.54 & 1.31 & $0.001^{*}$ & 68.19 & 68.14 & 1.00 & 0.976 & 44.13 & 43.36 & 1.02 & 0.631 \\
\hline Cocaine & 8.77 & 20.10 & 1.43 & $0.001^{*}$ & 54.39 & 51.03 & 1.07 & 0.1 & 41.44 & 37.24 & 1.11 & 0.066 \\
\hline Hallu & 16.89 & 11.36 & 1.49 & $0.001^{*}$ & 66.69 & 60.25 & 1.11 & 0.0 & 52.27 & 46.96 & 1.11 & 0.077 \\
\hline Heroin & 7.31 & 3.39 & 2.16 & $0.001^{*}$ & 22.84 & 19.66 & 1.16 & 0.406 & 17.82 & 13.59 & 1.31 & 0.223 \\
\hline \multicolumn{13}{|l|}{ Not in MSA } \\
\hline Marijuana & 3.51 & 4 & 1.3 & 0 . & 6 & 6 & 1. & 0 & 41.30 & & 1.00 & 0.960 \\
\hline Cocaine & 28.29 & 18.48 & 1.53 & $0.001^{*}$ & 49.26 & 46.83 & 1.05 & 0.147 & 35.87 & 34.27 & 1.05 & 0.317 \\
\hline Hallucinoge & 17.90 & 10.42 & 1.72 & $0.001^{*}$ & 65.15 & 62.32 & 1.05 & 0.194 & 49.95 & 49.90 & 1.00 & 0.984 \\
\hline Heroin & 7.35 & 3.19 & 2.30 & $0.001^{*}$ & 18.45 & 21.51 & 0.86 & 0.276 & 14.14 & 18.26 & 0.77 & 0.134 \\
\hline
\end{tabular}

From the National Household Surveys on Drug Abuse, 1991-1993 (aggregated).

aSee Table 2, footnote ${ }^{\text {a }}$.

${ }^{b}$ MSA, metropolitan statistical area (includes Chicago, Denver, Los Angeles, Miami, New York, and Washington, $\mathrm{DC})$.

drug use can be traced back to differences in prevalence of having an opportunity to try drugs and not to any sex or gender differences in the probability of initiating drug use once an opportunity to try the drug has occurred. Although we set out to identify potential subgroup variation in these results, our observed findings were highly consistent across subgroups defined by age/ $\mathrm{co}^{-}$ hort, race/ethnicity, geographic region of the United States, and urban or nonurban household status. Results also were consistent across all drugs studied, including marijuana, cocaine, hallucinogens, and heroin. Results suggest that females may not be more insulated than males against the likelihood of progression along the pathway of drug involvement but rather may only be at lower risk than males for initial exposure opportunities.

Interestingly, with respect to the unconditional probability of having an opportunity to try cocaine, hallucinogens, and heroin, there was no sex difference among 12-17-year-olds. For these drugs, sex differences may emerge later in development. Most likely, this is because most initial opportunities to try marijuana in the United States have occurred within the age category from 12 to 17 years, whereas initial opportunities to try the other drugs generally occur at the upper end of this age category or later (e.g., see U.S. mean values in 1993: marijuana at 16 years, hallucinogens at 17.5 years, heroin at 18 years, cocaine at 19 years). ${ }^{1}$ The finding that equivalent proportions of males and females make the transition from initial drug opportunity to initial drug use was observed across all age subgroups, even though sex differences were not yet apparent in the probability of exposure opportunity to most drugs by $12-17$-years-old.

Although results rather consistently illustrated male-female comparability in the conditional probability of drug use, given opportunity, and of rapid transition given opportunity, there were some exceptions. In fact, 10 of the 112 male-female comparisons examined showed significant sex effects, with all 10 favoring greater use and rapid transitions among males vs. females. Although these exceptions were specific to certain subgroups and drugs, this evidence of possible subgroup variation merits future work, first, in the form of replication and, second, if replicated, in the form of investigations to understand this 
anomalous variation where elsewhere there is no male-female difference.

These findings are interesting in light of two recent animal behavioral pharmacology studies of sex differences in drug reinforced behavior. In the first report, female rats were found to be more vulnerable to acquisition of cocaine and heroin self-administration than male rats. ${ }^{22}$ The second report examined reinstatement of cocaine self-administration behavior following drug priming, as a model for relapse to abuse. ${ }^{23}$ In that study, female rats were found to be more sensitive than male rats during the drug reinstatement phase. Similar to the present study, these animal findings raise questions about the long-standing assumption that males are at greater risk for drug use once drug self-administration opportunities become available.

\section{Limitations}

Several limitations of this work suggest other directions for future research, as outlined in our prior reports on this topic. ${ }^{1,2,20}$ In brief, this is an analysis of cross-sectional data. We look forward to future prospective research examining sex differences in transitions from initial drug opportunities to first drug use and regret that such data are not currently available. Another limitation is that there is no gold standard for measuring opportunity to try a drug nor for eventual use of a drug. Thus, we have had to rely on self-reported data about these experiences here as in other NHSDA reports. Also, the wording of the drug opportunity question is potentially confusing by inclusion of the concluding phrase "if you had wanted to" ("About how old were you when you first had the chance to try marijuana or hashish if you had wanted to?"). Although it is possible that this phrasing may induce measurement error, there is no reason to anticipate that the error would vary by sex of respondent, so that results of this study are unlikely to have been distorted by this measurement error. Finally, fine-grained time-to-event data were not available for the analysis of lag time from opportunity to first drug use. Such data would be valuable for a more sound definition of rapid transitions. More finegrained timing data would also enable time-toevent survival analyses, which are part of the research agenda we have proposed for the future.

A word about statistical power is in order. It is hard to imagine that deficient statistical power can account for our failure to observe male-fe- male differences in the probability of making a transition from an initial drug opportunity to an actual drug use. In this respect, heroin and hallucinogens represent limiting cases. In the NHSDA dataset under study, there were 4559 persons with an opportunity to try heroin and 11,337 persons with an opportunity to try hallucinogens. Hence, with sample sizes of this magnitude, lack of statistical power cannot be invoked to explain absence of statistical significance in this study. In further support of the conservative nature of our findings, we specifically did not do any Bonferroni adjustment or other correction for multiple comparisons, so as to avoid stacking the deck in favor of few significant male-female contrasts.

\section{CONCLUSIONS}

Notwithstanding these limitations, the data presented here provide additional evidence of no male-female differences in the transition from exposure opportunity to actual drug use. It is noteworthy that this finding is consistent across birth cohorts born from calendar year 1890 to as recent as 1981. This finding also seems to hold true for Caucasian, African American, and Hispanic respondents, for those living in the Northeast, North Central, Southern and Western United States, and for those inside and outside urban metropolitan areas at the time of interview.

As speculated in our earlier report, the observed sex differences in the likelihood of exposure to drug opportunities might be a function of different levels of parental monitoring of males vs. females, different levels of involvement in recreational or other activities associated with higher risk for drug exposure opportunities for males vs. females, or some other factor. ${ }^{2}$ The documented consistency of these results across NHSDA survey years ${ }^{2}$ and across many subgroups of the population argues for new research to probe the early emergence of these sex differences in drug involvement. This new research will lead us to a better understanding of male-female differences in the occurrence of drug use and dependence. More specifically, further research on early drug opportunities may highlight sex differences in the circumstances under which initial drug opportunities occur and possible sex differences in factors affecting decision to use, given the opportunity. Such research could directly translate into more tailored prevention ef- 
forts targeting factors most likely to set the stage for early drug opportunities and early transitions into use for males vs. females. In the meantime, to the extent that preventive efforts aim to reduce the likelihood of transitions from one stage of drug involvement to the next, the present research suggests that females warrant attention and preventive efforts as much as males.

\section{ACKNOWLEDGMENTS}

This research was supported by National Institute on Drug Abuse training grant DA07292 and research grant DA09592.

\section{REFERENCES}

1. Van Etten ML, Anthony JC. Comparative epidemiology of initial drug opportunities and transitions to first use: Marijuana, cocaine, hallucinogens, and heroin. Drug Alcohol Depend 1999;54:117.

2. Van Etten ML, Neumark YD, Anthony JC. Male-female differences in the earliest stages of drug involvement. Addiction 1999;94:1413.

3. United States Substance Abuse and Mental Health Services Administration (SAMHSA). National Household Survey on Drug Abuse, Summary of Findings: 1999, DHHS Pub. No. BKD376. Rockville, MD: Department of Health and Human Services, 2000.

4. Anthony JC, Warner LA, Kessler RC. Comparative epidemiology of dependence on tobacco, alcohol, controlled substances, and inhalants: Basic findings from the National Comorbidity Survey. Exp Clin Psychopharmacol 1994;2:244.

5. Eaton WW, Kramer M, Anthony JC, Dryman A, Shapiro S, Locke BZ. The incidence of specific DIS/ DSM-III mental disorders: Data from the NIMH Epidemiologic Catchment Area Program. Acta Psychiatr Scand 1989;79:163.

6. Hughes TL, Day E, Marcantonio RJ, Torpy E. Gender differences in alcohol and other drug use among young adults. Subst Use Misuse 1997;32:317.

7. O'Malley PM, Johnston LD, Bachman JG. Adolescent substance abuse: Epidemiology and implications for public policy. Pediatr Clin North Am 1995;42:241.

8. Brady KT, Grice DE, Dustan L, Randall C. Gender differences in substance use disorders. Am J Psychiatry 1993;150:1707.

9. Scourfield J, Stevens DE, Merikangas KR. Substance abuse, comorbidity, and sensation seeking: Gender differences. Compr Psychiatry 1996;37:384.

10. Powis B, Griffiths P, Gossop M, Strang J. The differences between male and female drug users: Community samples of heroin and cocaine users compared. Subst Use Misuse 1996;31:529.
11. Anglin MD, Hser YI, McGlothin W. Sex differences in addict careers. 2. Becoming addicted. Am J Drug Alc Abuse 1987;13:59.

12. Hser YI, Anglin MD, McGlothin W. Sex differences in addict careers. 1. Initiation of use. Am J Drug Alcohol Abuse 1987;13:33.

13. Grady K, Gersick KE, Snow DL, Kessen M. The emergence of adolescent substance use. I Drug Educ 1986; 16:203.

14. Lavik NJ, Huseby AB, Rud MG. Drug abuse and environment in youth: A study of a junior high school population in a county of Akershus, Norway. Soc Psychiatry 1985;20:179.

15. Stenbacka M, Allebeck P, Romelsjo A. Initiation into drug abuse: The pathway from being offered drugs to trying cannabis and progression to intravenous drug use. Scand J Soc Med 1993;21:31.

16. Zapata JT, Katims DS. Antecedents of subtance use among Mexican-American school-age children. I Drug Educ 1994;24:233.

17. United States Substance Abuse and Mental Health Services Administration (SAMHSA). National Household Survey on Drug Abuse, Main Findings: 1991, DHHS Pub. No. 1980. Rockville, MD: Department of Health and Human Services, 1993.

18. United States Substance Abuse and Mental Health Services Administration (SAMHSA). National Household Survey on Drug Abuse, Main Findings: 1992, DHHS Pub. No. 3012. Rockville, MD: Department of Health and Human Services, 1995.

19. United States Substance Abuse and Mental Health Services Administration (SAMHSA). National Household Survey on Drug Abuse, Main Findings: 1993, DHHS Pub. No. 3020. Rockville, MD: Department of Health and Human Services, 1995.

20. Van Etten ML, Neumark YD, Anthony JC. Initial opportunity to use marijuana and the transition to first use: United States, 1979 to 1994. Drug Alcohol Depend 1997;49:1.

21. Research Triangle Institute. SUDAAN: Software for the statistical analysis of correlated data. Research Triangle Park, NC, 1995.

22. Lynch WJ, Carroll ME. Sex differences in the acquisition of intravenously self-administered cocaine and heroin in rats. Psychopharmacology 1999;144:77.

23. Lynch WJ, Carroll ME. Reinstatement of cocaine selfadministration in rats: Sex differences. Psychopharmacology 2000;148:196.

Address reprint requests to: James C. Anthony, Ph.D. Johns Hopkins University, Department of Mental Hygiene Bloomberg School of Public Health Hampton House 893 624 N. Broadway Baltimore, MD 21205

E-mail: janthony@jhu.edu 


\section{This article has been cited by:}

1. Arbi Nazarian, Wei-Lun Sun, Luyi Zhou, Lynne M. Kemen, Shirzad Jenab, Vanya Quinones-Jenab. 2009. Sex differences in basal and cocaine-induced alterations in PKA and CREB proteins in the nucleus accumbens. Psychopharmacology 203:3, 641-650. [CrossRef]

2. V. S. Harder, E. A. Stuart, J. C. Anthony. 2008. Adolescent Cannabis Problems and Young Adult Depression: Male-Female Stratified Propensity Score Analyses. American Journal of Epidemiology 168:6, 592-601. [CrossRef]

3. Axel Perkonigg, Renee D. Goodwin, Agnes Fiedler, Silke Behrendt, Katja Beesdo, Roselind Lieb, Hans-Ulrich Wittchen. 2008. The natural course of cannabis use, abuse and dependence during the first decades of life. Addiction 103:3, 439-449. [CrossRef] 